\title{
Measurement and Utilization of Acoustic Emission for the Analysis and Monitoring of Concrete Slabs on the Subsoil
}

\author{
Luboš Pazdera1', Radim Cajka², Libor Topolář', Pavlina Mateckova², Vlastimil Bilek³, \\ Oldrich Sucharda ${ }^{3, *}$ \\ ${ }^{1}$ Institute of Physics, Faculty of Civil Engineering, \\ Technical University of Brno, Veveř́ 331/95, 60200 Brno, Czech Republic \\ 2 Department of Structures, Faculty of Civil Engineering, \\ VŠB-Technical University of Ostrava, Ludvíka Podéště 1875/17, 70833 Ostrava-Poruba Czech Republic \\ ${ }^{3}$ Department of Building Materials and Diagnostics of Structures, Faculty of Civil Engineering, \\ VŠB-Technical University of Ostrava, Ludvíka Podéště 1875/17, 70833 Ostrava-Poruba Czech Republic \\ *Corresponding author, e-mail: oldrich.sucharda@vsb.cz
}

Received: 15 June 2018, Accepted: 22 March 2019, Published online: 07 May 2019

\begin{abstract}
The article deals with the field of use of acoustic emission (AE) measurement in engineering structures. The research particularly focuses on the assessment of acoustic emission during an experimental test of the load-carrying capacity of concrete slabs on the ground. A wider field of research includes structural and material optimization of advanced engineering structures. The tests of concrete slabs are then carried out in an alternate solution which differs in the used concrete or steel fibre reinforced concrete (FRC). The experimental program then includes typical measurement methods using displacement sensors and strain gauges. Nondestructive methods of measurement including acoustic emission have been used with an eye to the configuration of the experiment and deeper understanding of the actual behaviour and damage to the structure allowing for subsequent optimization and non-linear simulation of slab computation. The aim of the submitted article is to present and assess the acoustic emission as a non-destructive method which can be used to detect damage and determine the load-bearing capacity of the selected type of a FRC structure.
\end{abstract}

Keywords

acoustic emission, concrete, monitoring, slab, subsoil, measurement, computation

\section{Introduction}

The utilization of typical verification and design models for concrete structures is a logical and comfortable solution in a majority of cases. However, there are situations where this is not possible. These include cases of advanced and innovative designs or detailed analyses of non-linear structural behaviour. This field is also included in a research task consisting in the development of advanced analysis methods and design optimization of concrete slabs $[1,2]$ with small thickness for the cases of high load [3]. The research program also comprises an extensive experimental program including laboratory tests and on-site testing. The approaches to the analysis and design of concrete structures using advanced numerical modelling are dealt with in the Model Code 2010 [4] recommendation which has been issued by the international organization CEB-FIB. There can be found the basic approaches to non-linear models of concrete. These namely include elastic-plastic [5], fracture mechanic [6] modified compression field theory for reinforced concrete [7] or combined [8] models.

The research itself then consists of an experimental program and measurement [3] and advanced computer modelling. The modelling is based on the use of a nonlinear analysis in combination with finite element method (FEM). The slab design optimization is then based on structural and material solutions using FRC (fibre reinforced concrete). For the use of FRC a detailed determination of the input mechanical and physical parameters in the wide scope and detailed knowledge of the behaviour during the application of load is required.

It is necessary to keep an eye to the fact that composites have different material properties based on the means of their stressing (tension, compression and shear) and 
that their deformation properties are of non-linear character. This fact must be properly taken into account in advanced analyses using non-linear behaviour. Classic beams from Bresler and Vecchio [9] for example, can serve as a good example of well-known and well-documented non-linear analyses and experiments. The analyses are then extended to include advanced three-dimensional non-linear models in [10].

Another important piece of knowledge regarding the behaviour of concrete slabs on the ground includes the information on the occurrence and spreading of cracks when the configuration of the experiment and the fact that the cracks occur in contact with the ground do not allow classic approach. On the other hand, the knowledge of occurrence and spreading of cracks is important for the validation of advanced computer simulations respecting non-linear behaviour.

However, the use of acoustic emission [11-13] presents itself as a method fit to gain a deeper understanding and achieve better identification of material disruption as it was used for concrete in selected cases [14] and [15]. The utilization of AE can also be important as a control element for the optimization of technologies [16]. Moreover, it is possible to use the AE for detailed and advanced monitoring [17] and analysis of engineering structures [18] or for new composites [19]. However, a wide field remains open for the new means of utilization of acoustic emissions with regards to the already performed research. The submitted article deals with one of these possibilities for concrete structures.

\section{Research significance}

The aim of the article is to assess the usability of acoustic emission measurement in experimental tests of concrete slabs on the subsoil for subsequent structural and material optimization using non-linear analysis and computer simulations. The main aims of acoustic emission measurement include identification of load application cycle in which initial cracks occur in the concrete and subsequent intensity of crack spreading in the concrete after reaching the threshold carrying capacity of the slabs. The research targets also include a definition of the amount of the released acoustic emission with regards to the various material composition of concrete which differs depending on the number of fibres. The performed measurements are also subsequently assessed with regards to the already performed numerical simulations and other measurements.

\section{Acoustic emission method}

The acoustic emission (AE) ranks among state-of-the-art methods for material engineering and stress applications [20]. AE can originate in many phenomena depending on the type of material. In metals, the acoustic emission sources may include dislocation movements, cracks, fractures and also corrosion processes. In concrete, these can cause microscopic and macroscopic damage as well as tear-off or movement of the reinforcing fibres. In FRC, the AE originate in matrix fracture, delamination, separation of the matrix from the fibres, fibre fracture and pulling out of fibres [21, 22]. Majority of acoustic emission sources are associated with damage. The detection and monitoring of emissions are normally used for the prediction of material failure. The acoustic emission method also used to be called stress wave emission. One of the basic parameters of acoustic emission is the change of ring down counting which can be considered/recorded:

$$
\frac{d n}{d t}=\alpha \times \Delta K_{I}^{m}
$$

where $\Delta K_{I}$ is the change of the stress intensity, $\alpha$ and $m$ constitute material constants. The cumulative number of ring down counting shows changes in the stress intensity on the material according to the integral equation:

$$
\int_{n_{0}}^{n} d n=\int_{t_{0}}^{t} \alpha \times \Delta K_{I}^{m} \times d t .
$$

One advantage of AE is that it is rather a global method which means that the technique follows a dimensional structure rather than a small local area [20]. As a result, the monitoring can be carried out in a short time and it is not work-demanding. However, this technology has a drawback - the AE depends on the gauge used. This means some discontinuities may not generate detectable acoustic emissions under certain types or levels of load. So far, the AE method had been used successfully in the monitoring of metals, composite materials, rocks and other materials. Compared to other non-destructive testing procedures the AE method monitors only active defects occurring inside the structure being monitored. The occurrence of active defects can be monitored particularly in concrete structures with regards to the fact that the initialization of cracks usually has no immediate and fundamental effect on the load capacity of the structure.

However, it may significantly influence the usable life of the structure due to the disruption of the concrete matrix structure. The defect can lead to the degradation of 
the material due to the environmental conditions, namely the surrounding earth in the case of concrete slabs. The failures may occur only when applying a load of the monitored structure. Passive defects or shape of the structure have no significant influence on the AE location. The acoustic emission occurs in the AE source only when energy is released due to internal or external stimulation $[21,23]$ and [24].

The AE event is emitted by non-recurring dislocation and degradation processes in the microstructure and macrostructure of the material. The released energy is transformed into a mechanical tension impulse travelling through the material as an elastic longitudinal or transversal wave. As soon as the wave hits the surface of the material, it partly bounces and is partly transformed into one or multiple modes. In slab structures, the wave travels namely through Rayleigh, i.e. surface wave. Besides the surface wave, there is also a transformation into e.g. Lamb, i.e. a plate wave. Each of these waves then spreads with different speed. The signal detected with the AE sensor and transferred into an electric signal is called AE signal [21].

The AE method differs from the majority of other non-destructive methods in two main things. Firstly, the signals occur in the material itself and do not come from an external source. This is in contrast to other non-destructive methods, such as ultrasound, which study the response to the signal introduced into the sample [25]. Secondly, AE detects the newly occurring defects whereas a majority of the methods detects the existing geometric discrepancies [24].

\section{Optimized design and analysis of concrete slabs}

Among the most important associations for concrete and construction materials are FIB (International Federation for Structural Concrete) and RILEM (International Union of Laboratories and Experts in Construction Materials, Systems and Structures) [26], which issued a number of important recommendations [4]. FRC is very often used in the design of constructionally and materially optimized concrete structures. However, FRC itself has a range of varieties differing in material and shape of the fibres [27-29].

Another important aspect is a detailed knowledge of material properties from laboratory tests, like residual tensile strength [30-35], which can be determined according to $[32,34]$. Extra sensitive information concerning material properties namely includes fibre concrete strength in a single axis tension, fracture energy or stress-strain diagram. The definition of these properties is dealt with by many authors [36-41] whereas their testing is very demanding. There is often a dispersion in the measured data when the more detailed information for selected materials can be found in [42, 43]. This subsequently complicates the creation of advanced material models for numerical simulations of the actual behaviour.

These include a case of non-linear analysis and a finite element method where a detailed calculation model and a more comprehensive description of the actual behaviour of the material [44] are required. Fracture mechanics [45] is then used for the description of concrete. Questions of mutual comparison or validation of calculations with experiments also often occur. It is particularly difficult to note the formation and spreading of cracks in cases such as a slab on the subsoil.

For the relevant research program, the total of 8 alternatives of laboratory tests altogether had been selected for the FRC used. These allowed sufficient description of the behaviour of FRC for the subsequently selected model of concrete. Details concerning the laboratory tests and results are summarized in [3]. C25/30 XC2 S3 had been selected as the initial matrix for the composite in conformity with classification [4]. Detailed properties were then summarized in Table 1. The maximum grain size in the concrete mixture was $16 \mathrm{~mm}$ and the water-cement ratio was 0.6. Portland cement $42.5 \mathrm{MPa}$ was used for the concrete. The concrete also contained Stacheplast plasticizer. The basic material properties are shown in Table 2 and the shape of the fibre in Fig. 1. The concrete was produced in the concrete plant and imported in the truck concrete mixer (Fig. 2).

Table 1 Material properties of concrete [3]

\begin{tabular}{lc}
\hline Consistency & S3 \\
\hline Cement & CEM I 42.5 R \\
Minimum cement content & $300 \mathrm{~kg}$ \\
Water-cement ratio: w/c & 0.6 \\
Aggregates 0/4 & $870 \mathrm{~kg}$ \\
Aggregates 4/8 & $150 \mathrm{~kg}$ \\
Aggregates 8/16 & $820 \mathrm{~kg}$ \\
Water & 1891 \\
Plasticizer & 2.91 \\
\hline
\end{tabular}

Table 2 Material properties of Dramix fibres 3D 65/60 BG [3]

\begin{tabular}{lc}
\hline Tensile strength: $R_{m, n o m}$ & $1160 \mathrm{~N} / \mathrm{mm}$, Tolerances: $\pm 7,5 \%$ Avg \\
\hline Young's Modulus $\left(E_{\text {mod }}\right):$ & $210000 \mathrm{~N} / \mathrm{mm}$ \\
Amount & 3200 Fibres $/ \mathrm{kg}$ \\
Length & $60 \mathrm{~mm}$ \\
Diameter & $0.9 \mathrm{~mm}$ \\
\hline
\end{tabular}




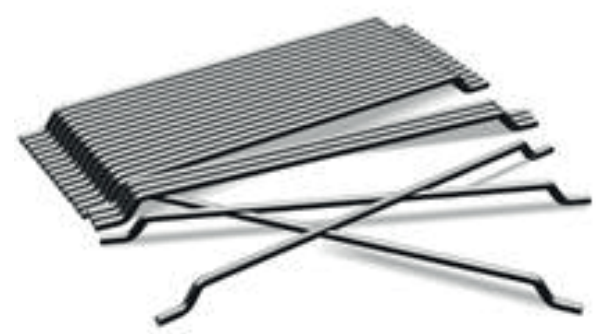

Fig. 1 Fiber Dramix 3D 65/60 BG [3], [48]

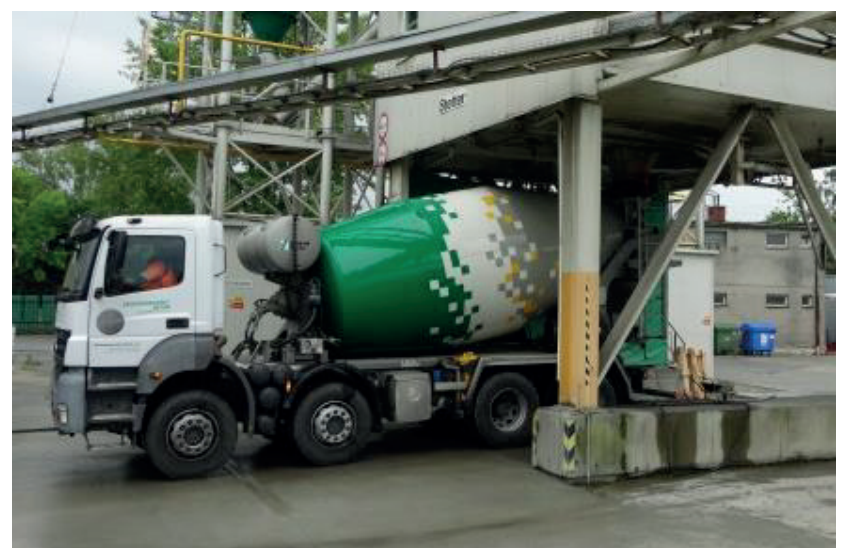

Fig. 2 Truck concrete mixer

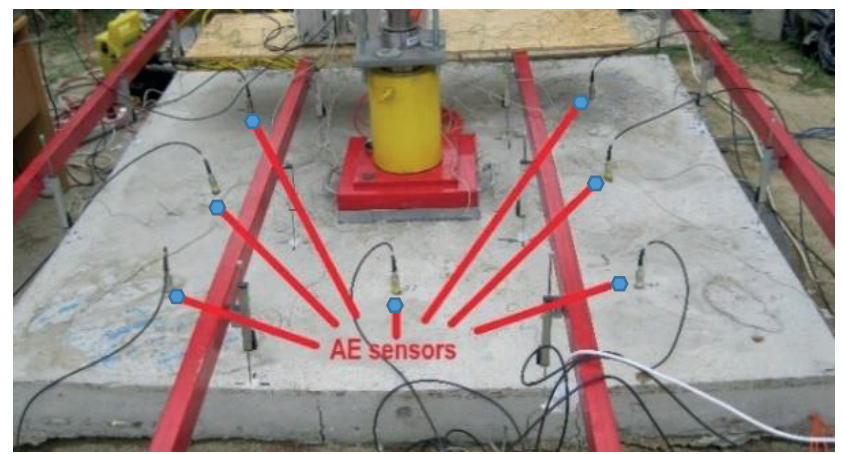

Fig. 3 The positioning of AE sensors on the tested concrete slab

The laboratory tests were fluently followed by an on-site experimental program for concrete slabs (Fig. 3) and advanced numerical modelling considering the non-linear beha-viour of the selected FRC. Three experiments were carried out altogether with acoustic emission measurement.

These differed only in the concrete composite used. The initial variant contained plain concrete only. The other slabs used in the acoustic emission measurement contained 25 and $50 \mathrm{~kg}$ of fibres.

The non-linear analysis was based on the approaches stated in Model Code 2010 [4]. Particularly, a three-dimensional computer model of a concrete slab on the ground was selected and the structural model of concrete was based on fracture-plastic theory and ATENA program [46]. The 3D Non-Linear Cementitious 2 [8] variant of the concrete model was used. The on-site experimental program was based on the solved construction task and the potential of testing devices. The basic dimensions of the concrete slab on the ground were $2 \times 2 \mathrm{~m}$, which sufficiently represents the case being solved. The nominal thickness of the slab was $150 \mathrm{~mm}$. The load spread area dimensions were $400 \times 400 \mathrm{~mm}$. The application of load on the slabs was performed in stages. One load application stage lasted 30 minutes had size $75 \mathrm{kN}$.

Displacement sensors have been used to measure vertical movement with regards to the possibilities of measurement and recording of tests. However, these do not allow the identification of the formation of cracks during the testing at the bottom surface of the slab which is in contact with the earth. It is only possible to perform an inspection of the disruption after the test (see Fig. 4). Due to this reason, it was decided to use acoustic emission measurement which included eight sensors altogether.

The view of the selected slab on the sensor is visible in Fig. 3. The three-dimensional model for the analysis included all fundamental parts of the load application test, while the selected part of the slab model is in Fig. 5. It was a concrete slab, steel loading slab and the subsoil. Further details are available in [3]. The scheme of slabs show in Fig. 6.

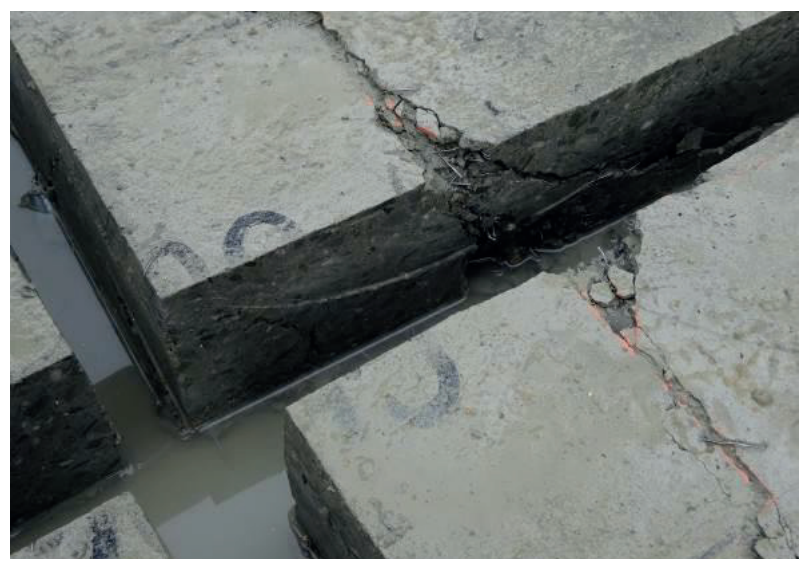

Fig. 4 Concrete center slab G04 - Crack [3]

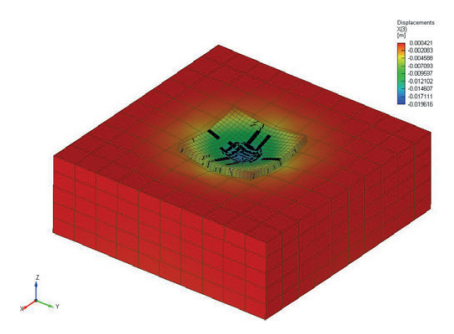

Concrete slab and subsoil

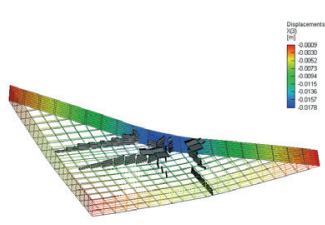

Concrete slab
Fig. 5 Slab G01 - Results - crack + deformation (half of model) 
G01_12.5.2016 Displacement sensors

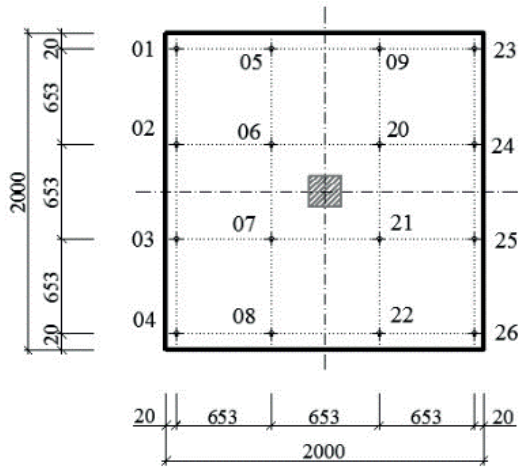

G03_23.8.2016 Displacement sensors

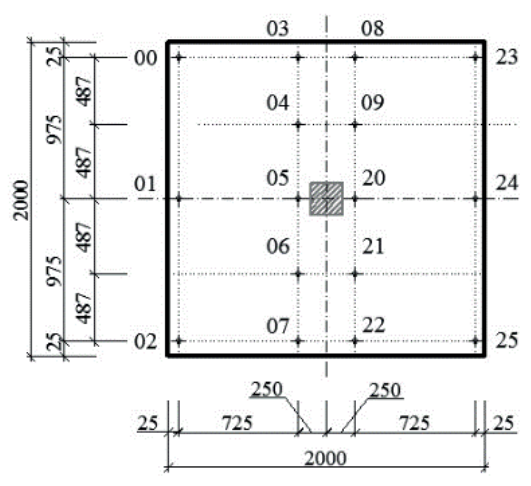

G02_22.6.2016 Displacement sensors

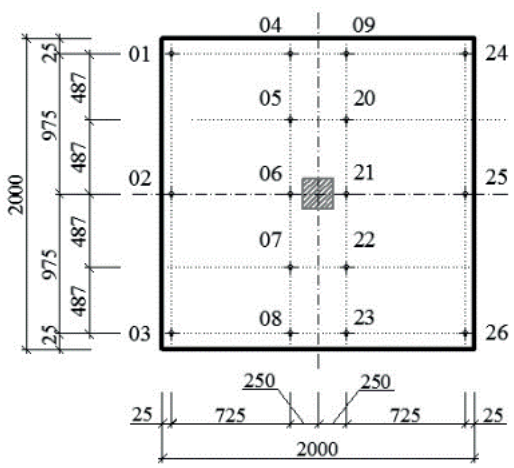

G01-G03 Acoustic emission sensors

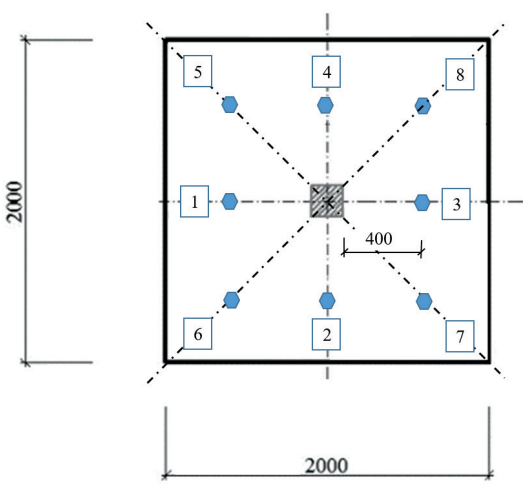

Fig. 6 Experimental slab G01 - 03 setups - displacement and AE sensors

\section{AE measurement description}

Eight sensors were used for the recording of AE signals together with an integrated $35 \mathrm{~dB}$ pre-amplifier (type MTPA-15 see Fig. 7) attached to the surface of the sample with beeswax. The bees wax ensures a very good acoustic bond between the uneven surface of the concrete and the sensor. Another advantage of beeswax is quick glueing of the sensor to the surface.

The DAKEL-XEDO ${ }^{\circ}$ universal measuring and diagnostic system developed by ZD Rpety-Dakel was used for the processing and recording of $\mathrm{AE}$ signals. The XEDO-AE unit used for the assessment of acoustic emission parameters. When connected to an acoustic emission sensor it allows measurement of standard AE parameters, processing of emission occurrences together with their localization and direct digital sampling of emission signals with the speed of up to $8 \mathrm{MHz}$. The AE waveform basic parameters are illustrated in Fig. 8

Signals with amplitudes below the operator-defined, minimum threshold will not be recorded. Duration is the delay between the first and last threshold crossings and the energy is directly proportional to the area under the acoustic emission waveform [47]:

$$
\text { AE energy } y_{i}=\int_{t_{0}}^{t_{t}} V_{i}(t)^{2} d t \text {, }
$$

where

$i$ is the recorded voltage transient $V(t)$ of a channel. $t_{0}$ is the starting time of the voltage transient record. $t_{1}$ is the ending time of the voltage transient record.

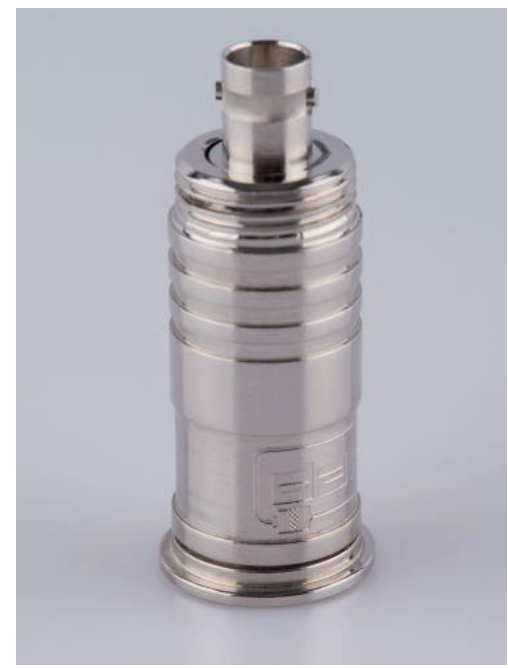

Fig. 7 AE sensor with an MTPA-15 type pre-amplifier 


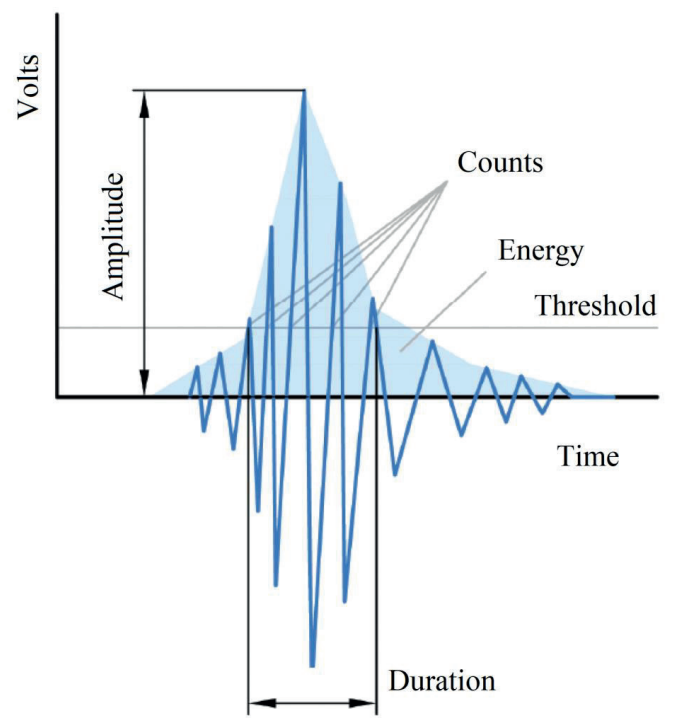

Fig. 8 Parameters reflected in an AE waveform [14]

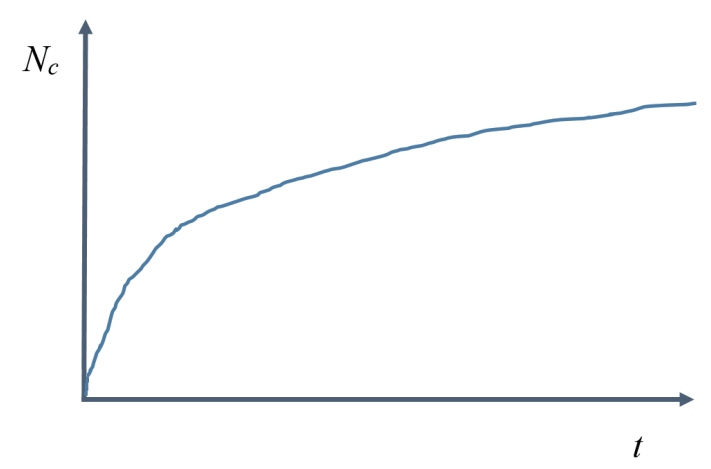

Fig. 9 Graphic diagram of time (t) history of the cumulative number of overshoots (NC) [11]
The AE activity assessment can be carried out continuously or subsequently, following the experiment. Graphic visualizations of the history chronologically showing the states of the selected parameters during measurement are used for the assessment.

Often a physical quantity (time, loading force, temperature, etc.) represents an independent parameter and an acoustic emission parameter (number of emission overshoots, amplitude, etc.) serves as the dependent quantity. The total AE activity from the beginning is often displayed as a cumulative parameter value, see Fig. 9 .

\section{Results and discussion}

The basic measurement parameters during the experimental tests were the load/time diagram in Fig. 10. The graph shows a well-visible peak and maximum load value. The peak load value is reached at the end of the loading cycle. Further is an interval of the experiment, where the deformation of the subsoil under the slab is increases and the load decreases to max. value.

From the measurement of acoustic emission at concrete slabs, it is possible to assess the signal of each sensor in the form of graphs in Fig. 11 which shows the dependency between the load and the acoustic emission. The black colour lines show concrete without fibres, blue lines are for concrete with $25 \mathrm{~kg}$ of fibres and green lines stand for concrete with $50 \mathrm{~kg}$ of fibres. However, it is beneficial for the summary assessment to use the graph in Fig. 12 which shows the number of overshoots depending on individual load application stages.

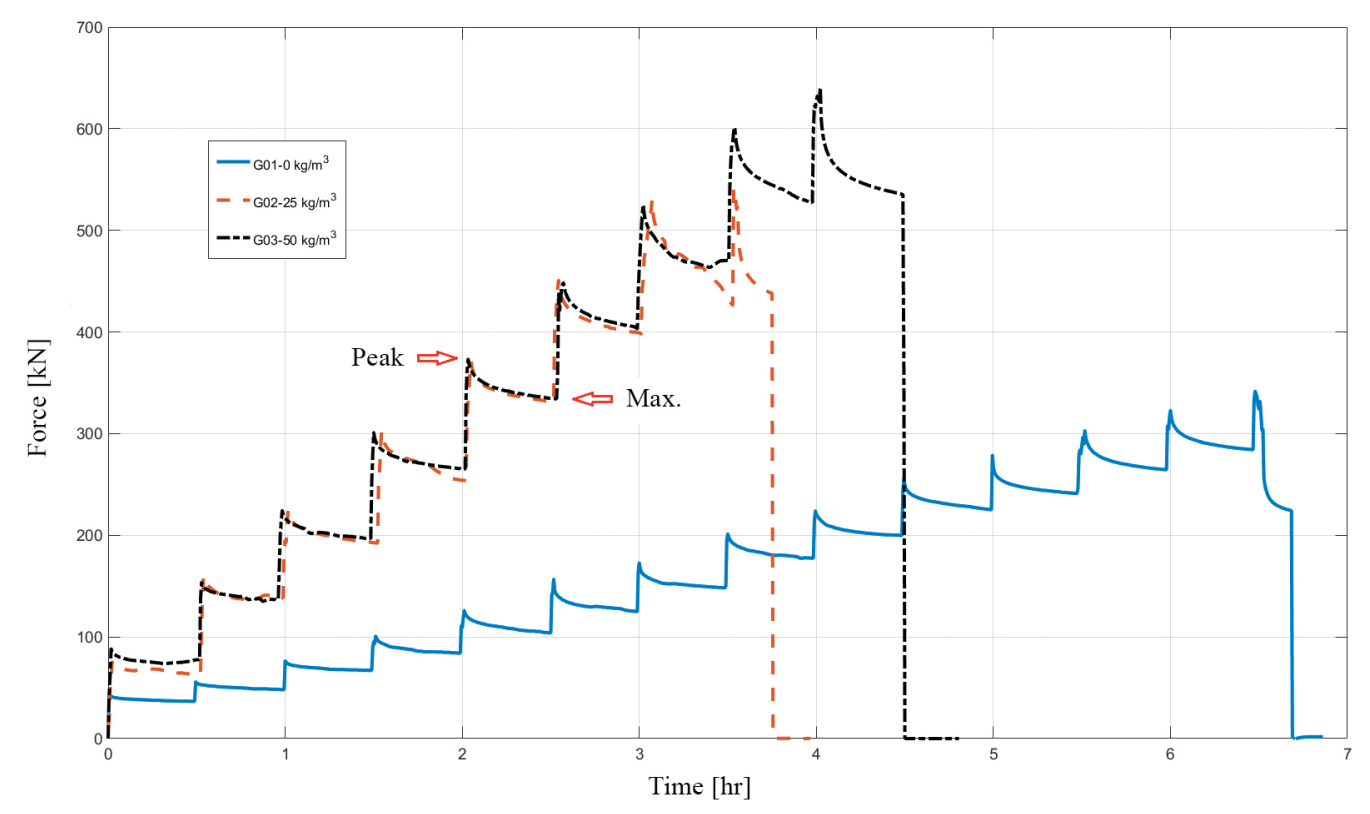

Fig. 10 Load - Time diagram of experiments for G01 - 03 

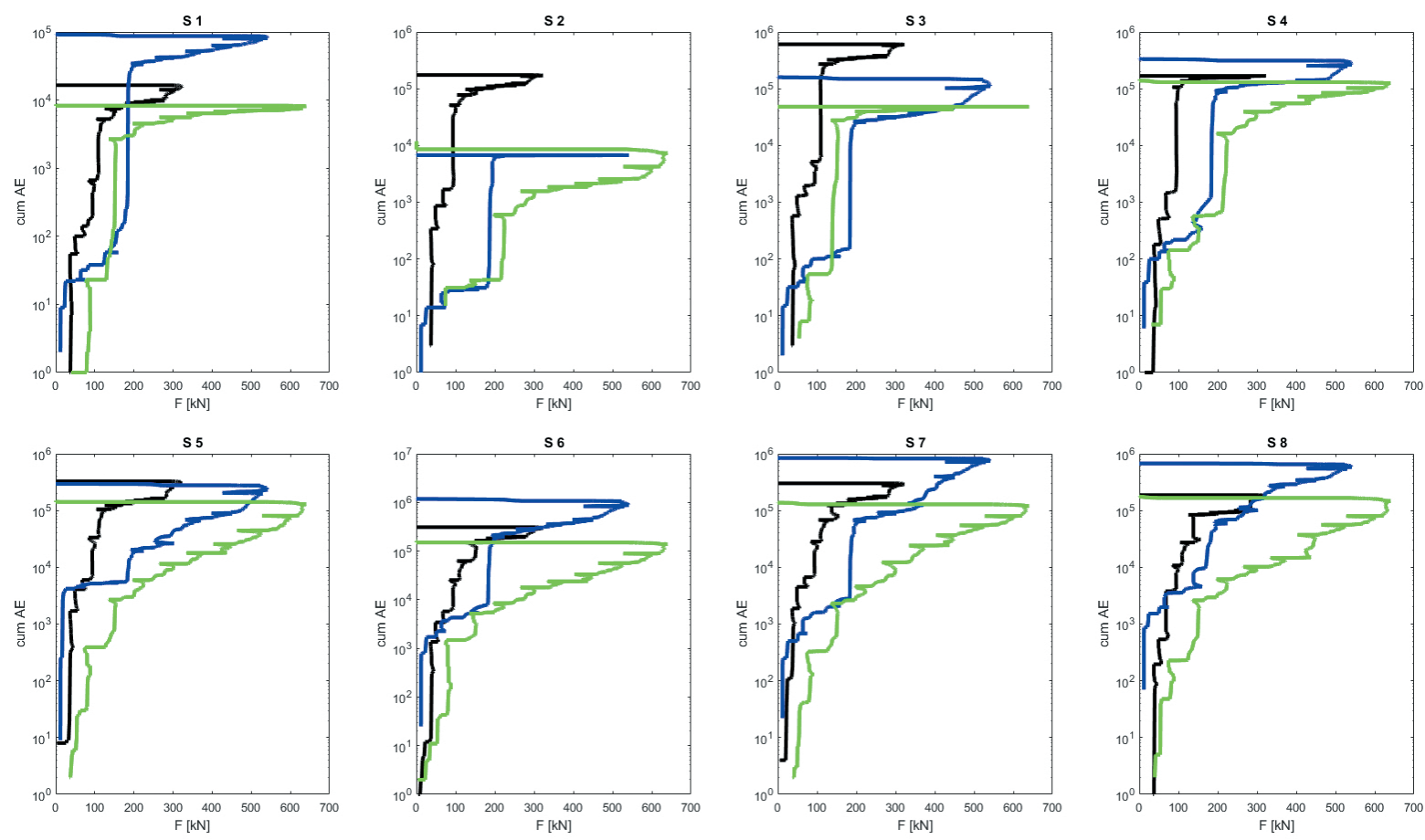

Fig. 11 Acoustic emission for individual sensors and slabs

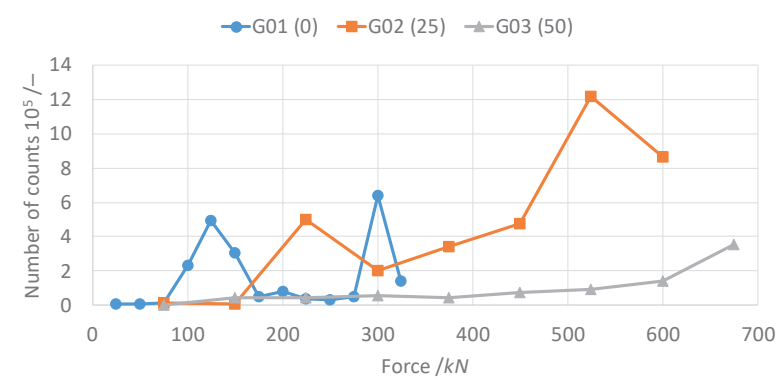

Fig. 12 The number of overshoots depending on individual load application stages

The graph implies that at the initial slab of plain concrete $\left(\mathrm{G} 01-0 \mathrm{~kg} / \mathrm{m}^{3}\right)$ there was a more notable AE activity during the application of load at the interval of 100 $150 \mathrm{kN}$ which was probably caused by the initiation of primary microcracks. At the following load application stages $(175-275 \mathrm{kN})$ the AE activity is lower, probably due to the fact that very few new cracks occur and there is rather an extension and propagation of the current network of cracks from the bottom surface to the top one. During the load application stage with the applied load of $300 \mathrm{kN}$, there is always a notable AE activity followed by the overall destruction of the slab.

To illustrate the course of acoustic emissions at individual sensors during the load test, the results are also processed in a three-dimensional graph in Fig. 13. The graph clearly implies higher acoustic emission upon the primary initialization of cracks and threshold carrying capacity of the concrete slab. Namely higher acoustic emission is then recorded at sensors 3, 4 and 8 upon the occurrence of the first cracks and sensors 3, 7 and 8 upon reaching the threshold carrying capacity. Notable cracks were then discovered in the areas where the sensors had been placed on the concrete slab.

The last recorded AE stage for the given concrete slab is $325 \mathrm{kN}$. The graph for the concrete slab $\left(\mathrm{G} 02-25 \mathrm{~kg} / \mathrm{m}^{3}\right)$ with $25 \mathrm{~kg}$ of fibres (Fig. 12) clearly implies that there was a notable AE activity at the third load application stage (200-225 kN) when the first (visually imperceivable) damage of the material matrix probably occurred. In the following stages $(300,375,450 \mathrm{kN})$, the $\mathrm{AE}$ activity was lower again which had probably been caused by the spreading of cracks and continuous drawing of the fibre out of the matrix. The AE activity was at its peak at the application of a load of about $525 \mathrm{kN}$ which was caused by the total and irreversible failure of the structure. Just like with the plain concrete slab, the last recorded stage $(600 \mathrm{kN})$ was nearly useless from the AE point of view. The acoustic emission results for individual sensors are displayed in Fig. 14. It is obvious that the intensity of acoustic emission is different for individual sensors and loading steps.

As for the concrete slab $\left(\mathrm{G} 03-50 \mathrm{~kg} / \mathrm{m}^{3}\right)$ with $50 \mathrm{~kg}$ of fibres, it has to be noted at the beginning that no total destruction of the slab occurred. The recorded AE activity is therefore notably lower than that measured in the 
case of the previous slabs for the whole time of the test. The first very small but recognizable acoustic emission can be detected with loads ranging between 150 and 250 $\mathrm{kN}$. With regards to the size and intensity of the acoustic emission this probably represents only minimum localization of the failure of the fibre concrete matrix. A more notable AE activity occurred only when the $600 \mathrm{kN}$ load had been applied; It was also caused by cracks, considering the scope of damage to the structure. However, it can be assumed that the course of AE emission activity would be similar to that of slab $\mathrm{G} 02-25 \mathrm{~kg} / \mathrm{m}^{3}$, although the loading forces would have to be higher.

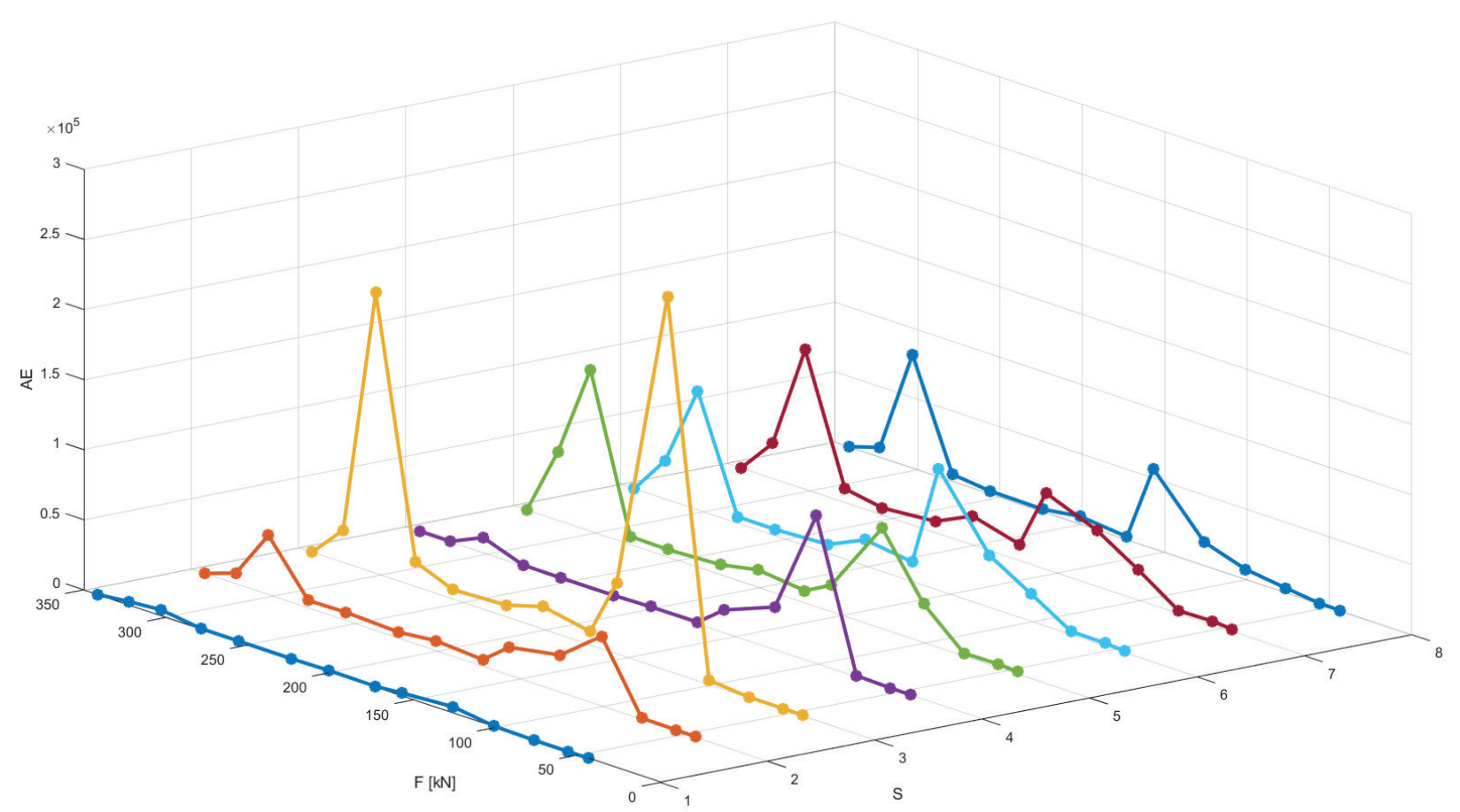

Fig. 13 Acoustic emission at concrete slab G01-0 kg/m $\mathrm{m}^{3}$ for individual sensors during testing
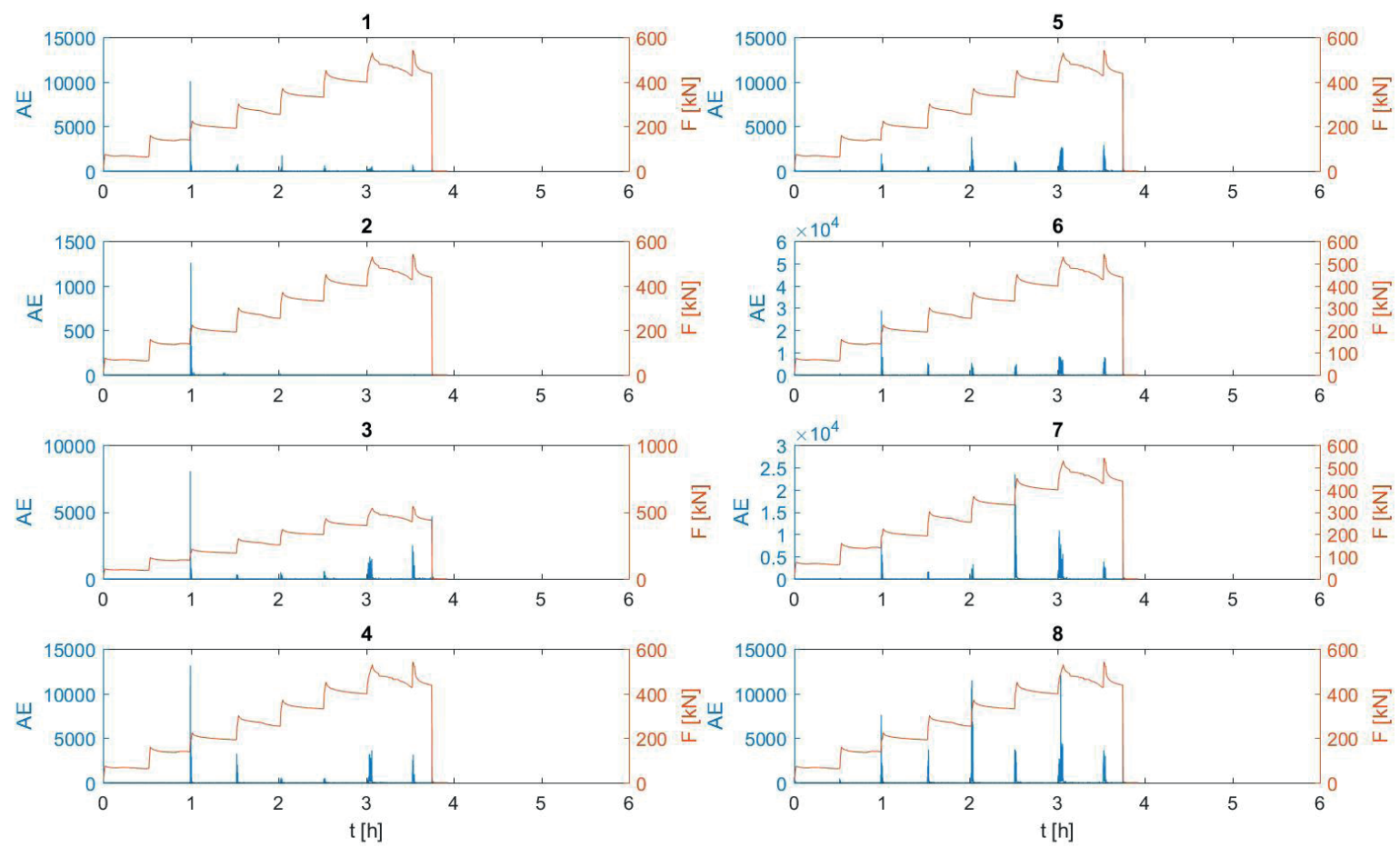

Fig. 14 Acoustic emission for G02 - $25 \mathrm{~kg} / \mathrm{m}^{3}$ (red), individual sensors 
Table 3 Numerical end experimental results

\begin{tabular}{|c|c|c|c|c|c|c|}
\hline $\begin{array}{l}\text { Slab number } \\
\left(\text { fibre } \mathrm{kg} / \mathrm{m}^{3} \text { ) }\right.\end{array}$ & $\begin{array}{l}\text { Load Peak } \\
\text { Exp. [kN] }\end{array}$ & $\begin{array}{l}\text { Load Max. } \\
\text { Exp. [kN] }\end{array}$ & $\begin{array}{c}\text { Bearing capacity } \\
\text { increased }[\mathrm{kN}]\end{array}$ & Calc. $[\mathrm{kN}]$ & $\begin{array}{l}\text { First important } \\
\text { AE }[\mathrm{kN}]\end{array}$ & $\begin{array}{c}\text { Major Important } \\
\mathrm{AE}[\mathrm{kN}]\end{array}$ \\
\hline G01 - 0 & 345 & 296 & - & 265 & $100-150$ & 300 \\
\hline G02 - 25 & 542 & 478 & 182 & 456 & $200-225$ & 525 \\
\hline G03 - 50 & 640 & 550 & 286 & 561 & $150-250$ & 600 \\
\hline
\end{tabular}

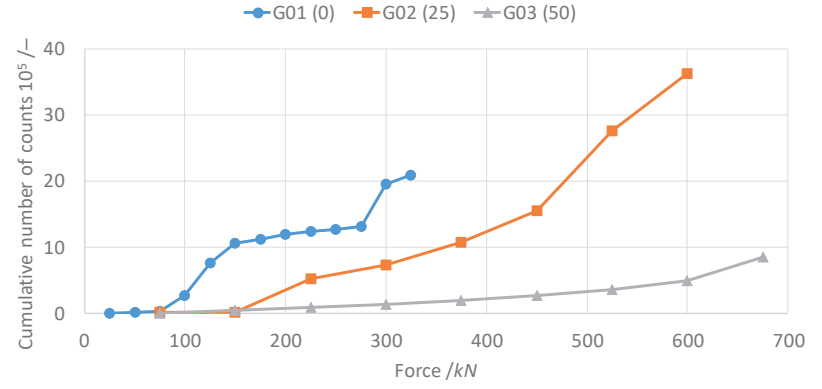

Fig. 15 The cumulative number of overshoots depending on individual load application stages
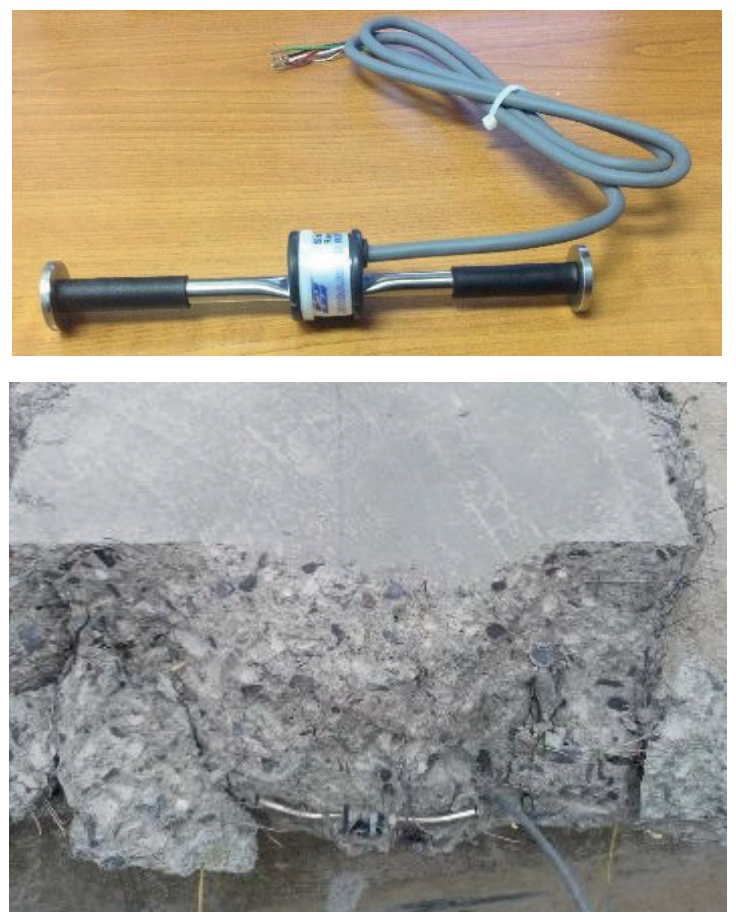

Fig. 16 The EDS_20V_Estrain gages used for the measurement, a damaged strain gage after the completion of measurement

In the graph (Fig. 15), the trend of increasing number of overshoots in individual loading steps for individual slabs is visible. The steeper parts of the cumulative curves characterize the formation of new microcracks. It is also visible that after a steep growth at plain concrete (G01 - 0 $\mathrm{kg} / \mathrm{m}^{3}$ ) the AE activity is reduced. In comparison, the AE activity at slabs reinforced with fibres (G02-25 kg/m $\mathrm{m}^{3}$ and $\mathrm{G} 03-50 \mathrm{~kg} / \mathrm{m}^{3}$ ) is continuous which is probably caused by the fibres being pulled out of the matrix after its failure. A summary of the results from the acoustic emission measurements and advanced numerical computations with the nonlinear analysis is given in Table 3 . The table shows the results of measuring peak and maximum load capacity of concrete slab. Results from already performed numerical calculations are also presented. The most important part of the table shows the load for the first significant acoustic emission (first cracking in concrete) and the main acoustic emission (maximum load capacity).

\section{Strain gage measurements - strain gauges}

In order to verify the behaviour and define the deformation in experimental tests of engineering structures, strain gauges are also used and were used also in the tests carried out with the selected slabs. Particularly, these were slabs with fibres G02 (S01) and G03 (S02). Resistance or string strain gages are used most frequently for the measurement of concrete structures. With the eye on the configuration of the experiment, the strain gage measurement was carried out using string strain gages, type EDS_20V_E, Fig. 16 located at the bottom surface of the slab, the area location is visible in Fig. 17.

The principle of measurement with wire strain gages is based on the measuring of the frequency of the wire which changes depending on the strain. In the case of the used strain gage, the range of measurement is $\pm 1500 \mathrm{~m}$ strain.

Fig. 18 graphically shows the assessed tension in the G02 (S01) and G03 (S02) slabs during load application. The graph clearly shows a load application stage where there was a notable increase of tension and the occurrence of cracks in the concrete. With the G02 slab there was a notable increase of tension during the load application stage around $150 \mathrm{kN}$ and with the G03 slab, the notable increase of tension appeared already at $75 \mathrm{kN}$ in points $\mathrm{T} 1$ and T4 and during the second stage of load application with the load of about $150 \mathrm{kN}$ for points T2 and T3. The difference in the measured values can be explained by the fact that the initial cracks were located on one side of the slab. Once the cracks appear, the strain gage measurements have no direct physical significance and they rather express equivalent tension in the crack in the structure. 

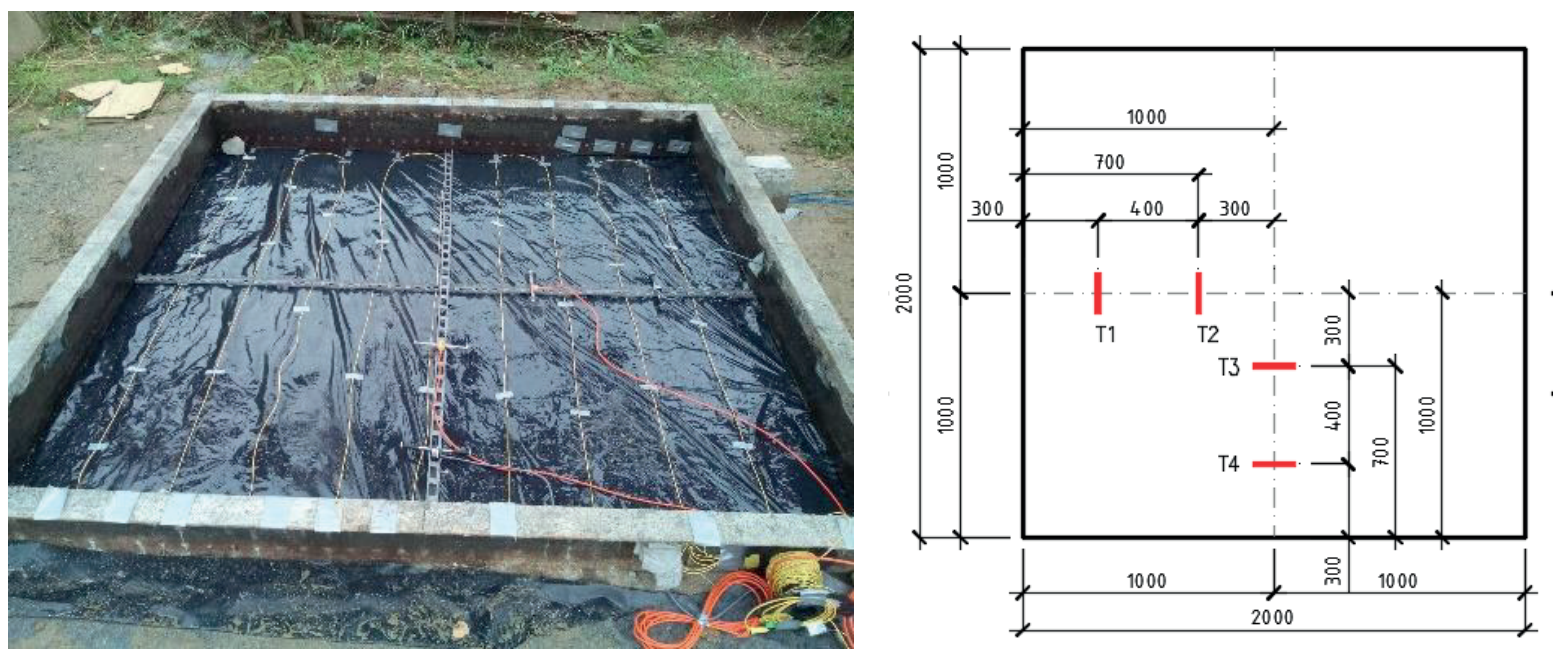

Fig. 17 Location of a strain gages on the fibre concrete slab
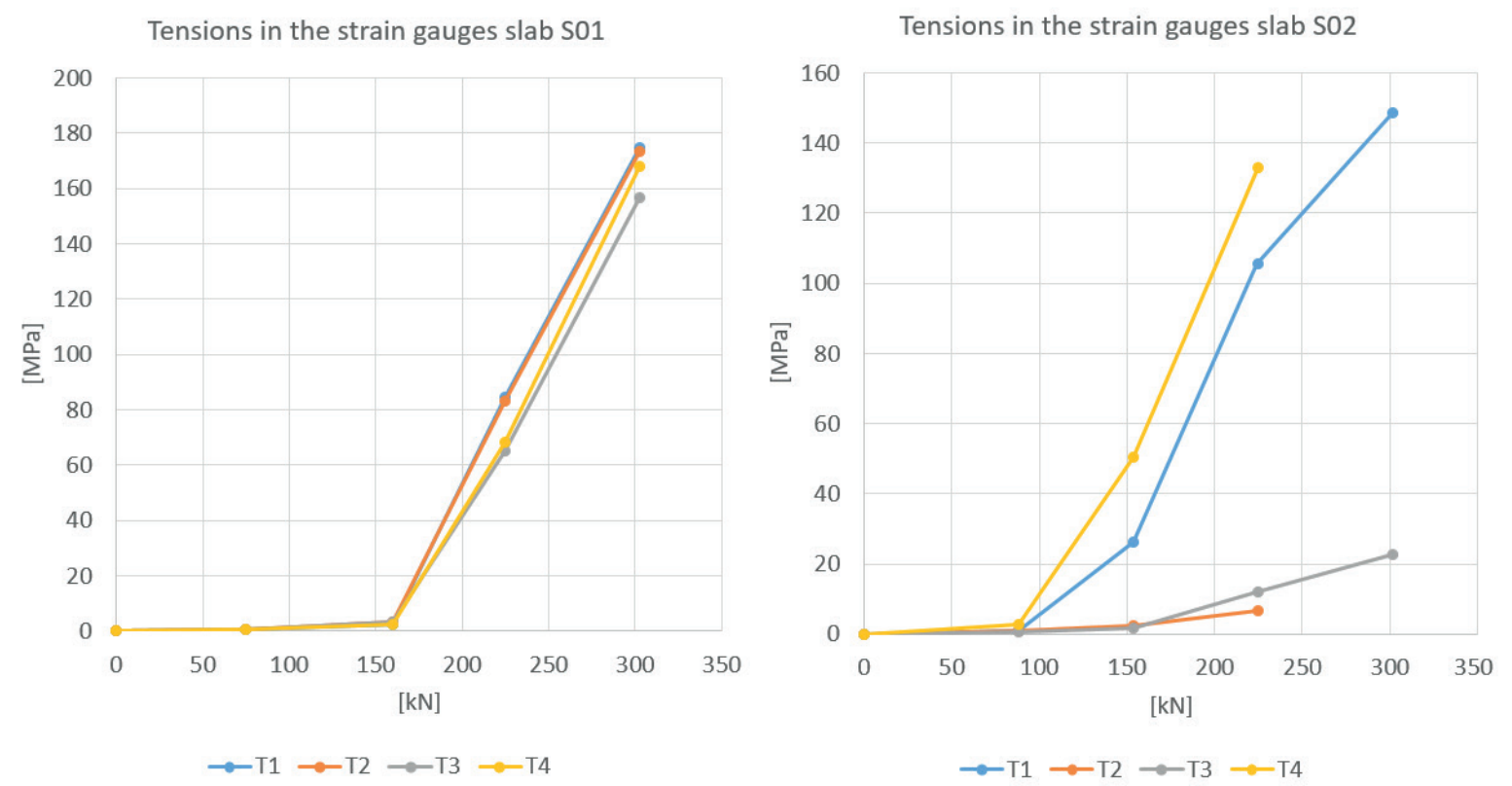

Fig. 18 Tension in strain gages as a function of applied load, slab G02 - 25 (S01) a G03 - 50 (S02)

\section{Conclusions}

The performed acoustic emission measurements have proven the usability of the selected method with concrete slabs on the ground for the identification of crack occurrence during the load application test. It is especially suitable in cases when the cracks in the concrete cannot be visibly identified or noticed. Using acoustic emission measurement, it was possible to define at which stage of load application the first cracks started to appear at the bottom surface of the slab and also determine the acoustic emission upon reaching the peak carrying capacity of the slabs. This cannot be simply verified visually concerning the configuration of the experiment, even though it is very important for subsequent numerical modelling which takes the actual behaviour into consideration. It is further possible to see the gradual development of cracks from the bottom to the top via acoustic emission measurement. It has been proven that the size of acoustic emission also differed depending on the concrete used with the different dosage of fibres. The summary results from the acoustic emission have also significantly contributed to the validation of the already performed numerical modeling based on non-linear analyses whereas the acoustic emission contributed to better understanding of the gradual collapse of concrete slabs on the ground. The selected material and the means of disruption/ failure of the structure affects the intensity of the acoustic emission. In the case of less reinforced fibre concrete, the whole course of acoustic emission was recorded. At better 
reinforced concrete element there was a localization of cracks and termination of acoustic emission transmission at higher load intensities and more notable deformations. The variance between the performed experiments and subsequent numerical models can be attributed to the input influences whose nature has a stochastic character. Namely, in the case of the solved task and acoustic emission measurement, the assessment of results is influenced by the interaction between the concrete slab and the ground. Through comparing the assessment of the strain gauge measurement and acoustic emission it is can be stated that it is possible to determine the load interval in which the cracks appear at the bottom surface of the slab in contact with the subsoil.

- The conclusions of the measurement and the assessment of the acoustic emission can be further specified.

- It is possible to identify the occurrence of cracks in concrete and FRC using acoustic emission.

- The intensity of acoustic emission is different for concrete and FRC when the amount of reinforcement also influences the amount of acoustic emission - the number of overshoots.

- Areas with more notable disruption and occurrence of cracks can be localized by detailed analysis of individual results from the sensors.

- The use of acoustic emission is suitable namely in the cases when ordinary methods of monitoring disruption of engineering structures are not possible.

\section{References}

[1] Alani, A. M., Rizzuto, J., Beckett, D., Aboutalebi, M. "Structural behaviour and deformation patterns in loaded plain concrete ground-supported slabs", Structural Concrete, 15(1), pp. 81-93, 2014.

https://doi.org/10.1002/suco.201300043

[2] Siburg, C., Hegger, J. "Experimental investigations on the punching behaviour of reinforced concrete footings with structural dimensions", Structural Concrete, 15(3), pp. 331-339, 2014.

https://doi.org/10.1002/suco.201300083

[3] Sucharda, O., Bilek, V., Smirakova, M., Kubosek, J., Cajka, R. "Comparative evaluation of mechanical properties of fibre-reinforced concrete and approach to modelling of bearing capacity ground slab", Periodica Polytechnica Civil Engineering, 61(4), pp. 972-986, 2017.

https://doi.org/10.3311/PPci.10688

[4] fib CEB-FIP, "Model Code 2010 - Final draft, Volume 1" fib Bulletin, 65, Lausanne, Switzerland, 2012.

[5] Chen, W.-F. "Plasticity in reinforced concrete", McGraw-Hill, New York, NY, United States, 1982.

[6] Bazant, Z., Planas, J. "Fracture and size effect in concrete and other quasibrittle materials", 1st ed., CRC Press, Boca Raton, Florida, United States, 1998.
The selected type of concrete structure on the subsoil is a typical example.

- The intensity of acoustic emission intensity is influenced also by the type of disruption/failure of the structure.

- The acoustic emission results can significantly contribute to the validation of advanced numerical analyses which take into consideration the non-linear behaviour of the material.

From the results of the measurements and tests, the effect of the fibers on the development of concrete cracks and the size of the AE parameters is well evident. There is a further research area for qualified evaluation of collapse mechanisms and the effect of different fibers dosage. This was not possible with regard to the scope of the realized experimental program. Further research will focus on a more detailed outlook of AE parameters.

\section{Acknowledgement}

This outcome has been achieved with the financial support of project GACR No. 16-08937S "State of stress and strain of fibre reinforced composites in interaction with the soil environment". In this undertaking, theoretical results gained by the project of "The conceptual research and development 2018" at the Faculty of Civil Engineering, VŠB - Technical University of Ostrava were partially exploited.

[7] Vecchio, F. J., Collins, M. P. "The modified compression-field theory for reinforced concrete elements subjected to shear", American Concrete Institute Structural Journal, 83(2), pp. 219-231, 1986.

[8] Červenka, J., Papanikolaou, V. K. "Three dimensional combined fracture-plastic material model for concrete", International Journal of Plasticity", 24(12), pp. 2192-2220, 2008. https://doi.org/10.1016/j.ijplas.2008.01.004

[9] Vecchio, F. J., Shim, W. "Experimental and analytical reexamination of classic concrete beam tests", Journal of Structural Engineering, 130(3), pp. 460-469, 2004. https://doi.org/10.1061/(ASCE)0733-9445(2004)130:3(460)

[10] Sucharda, O., Konecny, P. "Recommendation for the modelling of $3 \mathrm{D}$ non-linear analysis of RC beam tests", Computers and Concrete, 21(1), pp. 11-20, 2018. https://doi.org/10.12989/cac.2018.21.1.011

[11] Pazdera, L., Topolar, L. "Application acoustic emission method during concrete frost resistance", Russian Journal of Nondestructive Testing, 50(2), pp. 127-131, 2014. https://doi.org/10.1134/S1061830914020065

[12] Ono, K. "Calibration Methods of Acoustic Emission Sensors", Materials, 9(7), 2016. https://doi.org/10.3390/ma9070508 
[13] Hamstad, M. A., "Acoustic Emission in Development of Composite Materials", In: Miller, R. K., McIntire, P. (eds.) NDT Handbook, Vol. 5, Acoustic Emission Testing, American Society for Nondestructive Testing, Columbus, Ohio, United States, 1987, pp. 561-568.

[14] Topolář, L., Pazdera, L., Kucharczyková, B., Smutný, J., Mikulášek, K. "Using acoustic emission methods to monitor cement composites during setting and hardening", Applied Sciences, 7(5), 2017. https://doi.org/10.3390/app7050451

[15] Lacidogna, G., Piana, G., Carpinteri, A. "Acoustic emission and modal frequency variation in concrete specimens under four-point bending", Applied Sciences, 7(4), 2017. https://doi.org/10.3390/app7040339

[16] Nosov, V. V. "On the principles of optimizing the technologies of acoustic-emission strength control of industrial objects", Russian Journal of Nondestructive Testing, 52(7), pp. 386-399, 2016. https://doi.org/10.1134/S1061830916070068

[17] Tanaka, Y., Maekawa, K., Maeshima, T., Iwaki, I., Nishida, T., Shiotani, T. "Data assimilation for fatigue life assessment of RC bridge decks coupled with path-integral-mechanistic model and non-destructive inspection", Journal of Disaster Research, 12(3), pp. $422-431,2017$. https://doi.org/10.20965/jdr.2017.p0422

[18] Invernizzi, S., Lacidogna, G., Carpinteri, A. "Numerical models for the assessment of historical masonry structures and materials, monitored by acoustic emission", Applied Sciences, 6(4), 2016. https://doi.org/10.3390/app6040102

[19] Agresti, E. M., Caneva, C., De Rosa, I. M., Sarasini, F., Valente, M. "Effect of jute fibres on post-impact behaviour of E-glass reinforced composites assessed through acoustic emission", International Journal of Materials and Product Technology, 3(1-4), pp. 30-46, 2009. https://doi.org/10.1504/IJMPT.2009.027818

[20] Acoustic Emission Working Group, [online] Available online: www. aewg.org [Accessed: 01.09.2017]

[21] Grosse, C. U., Ohtsu, M. (eds.) "Acoustic emission testing", 1st ed., Springer, Berlin, Germany, 2008. https://doi.org/10.1007/978-3-540-69972-9

[22] Ativitavas, N. "Acoustic emission signature analysis of failure mechanisms in fiber reinforced plastic structures", Doctoral dissertation, The University of Texas at Austin, Austin, Texas, United States, 2002. [online] Available at: http://hdl.handle.net/2152/442 [Accessed: 02.05.2019]

[23] Pollock, A. A. "Practical guide to acoustic emission testing", Physical Acoustic Corporation Publication, Princeton, New Jersey, Unites States, 1988.

[24] Pollock, A. A. "Acoustic emission inspection", Physical Acoustics Corporation, Rep. TR-103-96-12/98", 1989, pp. 278-294.

[25] Vallen, H. "AE Testing Fundamentals, Equipment, Applications", NDT.net, 7(9), 2002. [online] Available at: https://www.ndt.net/ article/v07n09/05/05.htm [Accessed:02.05.2019]

[26] RILEM "About Rilem" [online] Available at: https://www.rilem.net [Accessed:28.02.2019]

[27] Brandt, A. M. "Fibre reinforced cement-based (FRC) composites after over 40 years of development in building and civil engineering", Composite Structures, 86(1-3), pp. 3-9, 2008.

https://doi.org/10.1016/j.compstruct.2008.03.006
[28] Karatas, M., Gunes, A. "Engineering properties of self-compacting concrete produced by polypropylene and steel fiber", Periodica Polytechnica Civil Engineering, 59(2), pp. 95-102, 2015. https://doi.org/10.3311/PPci.7348

[29] Zarzycki, P. K., Katzer, J., Domski, J. "Fast classification of fibres for concretebased on multivariate statistics", Computers and Concrete, 20(1), pp. 23-29, 2017. https://doi.org/10.12989/cac.2017.20.1.023

[30] Deutscher Ausschuss für Stahlbeton "DAfStb - Richtlinie stahlfaserbeton" (DAfStb - Guideline for steel fiber reinforced concrete), DAfStb, Berlin, Germany, 2011. (in German)

[31] Ali, A., Iqbal, S., Holschemacher, K., Bier, T. A. "Effect of fibers on bond performance of lightweight reinforced concrete", Periodica Polytechnica Civil Engineering, 60(1), pp. 97-102, 2016. https://doi.org/10.3311/PPci.8080

[32] Vandewalle, L., Nemegeer, D., Balázs, Gy. L., Barr, B., Barros, J. A. O. et al. "RILEM TC 162 TDF: Test and Design Methods for Steel Fibre Reinforced Concrete - Design of Steel Fibre Reinforced Concrete Using the $\sigma-\mathrm{w}$ Method: Principles and Application", Materials and Structures, 35(249), pp. 262-278, 2002.

[33] Ponikiewski, T., Katzer, J. "Fresh mix characteristics of self-compacting concrete reinforced by fibre", Periodica Polytechnica Civil Engineering, 61(2), pp. 226-231, 2017. https://doi.org/10.3311/PPci.9008

[34] Balazs, L., Barr, B., Barros, J., Bartos, P., Banthia, N. et al. "RILEM TC 162-TDF: Test and design methods for steel fibre reinforced concrete. $\sigma-\varepsilon$-design method, Final Recommendation", Materials and Structures, 36(262), pp. 560-567, 2003. [online] Available at: https:// www.rilem.net/images/publis/1507.pdf [Accessed:02.05.2019]

[35] Kormaníková, E., Kotrasová, K. "Elastic mechanical properties of fiber reinforced composite materials", Chemicke Listy, 105(17), pp. 758-762, 2011. [online] Available at: http://w.chemicke-listy.cz/ docs/full/2011_17_s758-s766.pdf [Accessed:02.05.2019]

[36] Şahin, Y., Köksal, F. "The influences of matrix and steel fibre tensile strengths on the fracture energy of high-strength concrete", Construction and Building Materials, 25(4), pp. 1801-1806, 2011. https://doi.org/10.1016/j.conbuildmat.2010.11.084

[37] Sarfarazi, V., Ghazvinian, A., Schubert, W., Nejati, H. R., Hadei, R. "A new approach for measurement of tensile strength of concrete", Periodica Polytechnica Civil Engineering, 60(2), pp. 199-203, 2016. https://doi.org/10.3311/PPci.8328

[38] Wang, Y., Li, V. C., Backer, S. "Experimental determination to tensile behavior of fiber reinforced concrete", ACI Materials Journal, 87(5), pp. 461-468, 1990. [online] Available at: https:// www.researchgate.net/publication/280224218_Experimental_ Determination_of_Tensile_Behavior_of_Fiber_Reinforced_ Concrete [Accessed:02.05.2019]

[39] Hillerborg, A. "Analysis of fracture by means of the fictitious crack model, particularly for fibre reinforced concrete", International Journal of Cement Composites, 2(4), pp. 177-184, 1980.

[40] EN 14651:2005+A1:2007(E) "Test Method for Metallic Fibre Concrete - Measuring the Flexural Tensile Strength (Limit of Proportionality (LOP), Residual)", European Committee for Standardization, Brussels, Belgium, 2007. 
[41] Sucharda, O., Pajak, M., Ponikiewski, T. Konecny, P. "Identification of mechanical and fracture properties of self-compacting concrete beams with different types of steel fibres using inverse analysis", Construction and Building Materials, 138, pp. 263-275, 2017. https://doi.org/10.1016/j.conbuildmat.2017.01.077

[42] ISO 2394 (1998) "General principles on reliability for structures", International Organization for Standardization, Geneva, Switzerland, 1998

[43] JCSS "Probabilistic model code. JCSS working material", Joint Committee on Structural Safety, 2016. [online]. Available at: http://www.jcss.byg.dtu.dk/publications/probabilistic_model_code [Accessed:02.05.2019]

[44] ASCE "State-of-the-art report on finite element analysis of reinforced concrete", Task Committee on Finite Element Analysis of Reinforced Concrete Structures, Reston, Virginia, United States, Rep. No. 545, 1982.
[45] Karihaloo, B. L. "Fracture Mechanics and Structural Concrete" Long-man Scientific \& Technical, New York, NY, United States, 1995 .

[46] Červenka V., Jendele L., Červenka J. "ATENA Program documentation - Part 1: Theory", Cervenka Consulting, Prague, Czech republic, 2011. [online] Available at: http://www.technologismiki.com/uplx/ ATENA Theory.pdf [Accessed:02.05.2019]

[47] Sagar, R. V. "An experimental Study on Acoustic Emission Energy and Fracture Energy of Concrete", In: Proceedings of the National Seminar \& Exhibition on Non-Destructive Evaluation, Bangalore, India, 10-12, December, 2009.

[48] Bekaert "Dramix ${ }^{\circledR}$ steel fiber concrete reinforcement" [online] Available at: https://www.bekaert.com/ [Accessed:02.05.2019] 